\title{
Solid-Phase Luminescence Determination of Tetracycline in Bottled Water Using Chemically Modified Silica
}

\author{
L. A. Goncharova ${ }^{a}$, N. G. Kobylinska ${ }^{a, *}$, M. E. Díaz-Garcia ${ }^{b}$, and V. N. Zaitsev ${ }^{a}$ \\ ${ }^{a}$ Taras Shevchenko National University of Kyiv, Kyiv, 01601 Ukraine \\ ${ }^{b}$ University of Oviedo, Oviedo, 33006 Spain \\ *e-mail: kobilinskaya@univ.kiev.ua
}

Received August 18, 2016; in final form, January 31, 2017

\begin{abstract}
Possibility of using chemically modified silica (CMS) with covalently immobilized sulfonic and ethylenediaminetriacetate (ED3A) groups for the adsorption preconcentration and extraction of tetracycline (TC) from aqueous solutions is studied. The conditions of complex formation by europium(III) ions on the surface of these adsorbents are optimized. The effect of citrate and $\mathrm{Eu}^{3+}$ ions on the luminescence intensity of the $\mathrm{Eu}-\mathrm{TC}$ complex is shown. The luminescence properties of $\mathrm{SiO}_{2} \mathrm{ED} 3 \mathrm{AEu}$ and $\mathrm{SiO}_{2} \mathrm{SO}_{3} \mathrm{HEu}$ systems with tetracyclines are studied depending on the acidity of the medium, time of phase contact, the ratio of the volume of the solution to the weighed portion of the adsorbent, and concentrations of the adsorbed substances. It is found that tetracycline is quantitatively extracted by CMS as a complex with europium(III) ions in $\mathrm{pH}$ range $6.5-8.0$; adsorption capacity to tetracycline in the Henry region is as high as $0.07-0.09 \mathrm{mmol} / \mathrm{g}$ and partition coefficients are $10^{3}-10^{4} \mathrm{~mL} / \mathrm{g}$. A procedure is developed for the solid-phase luminescence determination of tetracycline using $\mathrm{SiO}_{2} \mathrm{SO}_{3} \mathrm{HEu}$ and $\mathrm{SiO}_{2} \mathrm{ED} 3 \mathrm{AEu}$ systems with limits of detection of 0.8 and $2.0 \mathrm{nM}$, respectively; linearity range is $1 \times 10^{-9}-1 \times 10^{-5} \mathrm{M}$. The procedure is tested in the analysis of model mixtures and samples of bottled water.
\end{abstract}

Keywords: tetracycline, antibiotics, adsorption preconcentration, sensitized luminescence, bottled water DOI: $10.1134 / \mathrm{S} 106193481707005 \mathrm{X}$

Antibiotics are widely used in the food industry, including bottled water, as antibacterial and antifungal preparations $[1,2]$. In bottling mineral water from tanks, the sterility of the system is maintained by passing antibiotics, which partially get into water [1]. Antibiotics are present in sewage waters of enterprises, municipal sewages, underground waters, and soils [3, 4], and also in drinking water [5]. According to the data of water monitoring, the most widespread pollutants among antibiotics are antibacterial preparations of the tetracycline series: oxytetracycline [6], tetracycline [7], chlortetracycline [8], and doxycycline in concentrations from 10 to $30 \mathrm{ng} / \mathrm{L}$.

The continuous consumption of even insignificant amounts of antibiotics leads to the emergence of allergic reactions and disorders of intestinal microflora, which is accompanied by a decrease in the activity of enzymes and the deterioration of vitamin digestion [9] and also causes the resistance of bacteria to antibiotics [10]. The use of drinking water containing even trace amounts of antibiotics considerably accelerates the development of bacterial resistance [2].

Immunological and microbiological tests specific to each of group of antibiotics, for example, Tetra Star (sensitivity to tetracycline antibiotics $60-80 \mu \mathrm{g} / \mathrm{kg}$, duration of analysis $10 \mathrm{~min}$ ), Beta Star Combo (sensitivity $2-50 \mu \mathrm{g} / \mathrm{kg}$, duration of analysis $5 \mathrm{~min}$ ), etc., have received the widest distribution for the control and determination of antibiotics [11]. The most sensitive method for the control and selective determination of antibacterial preparations at the level of their maximum permissible concentration (MPC) in drinking water and environmental samples is HPLC with UV, fluorescence, or mass spectrometry detection [12-14]. However, this method is the least available because of the high cost of equipment and service. A great number of studies were devoted to methods based on the sensitized luminescence of Eu(III) or $\mathrm{Tb}$ (III) in solution [15, 16] or in the solid phase [17]. The procedures are characterized by high sensitivity, simplicity and selectivity, especially to antibiotics of tetracycline and quinoline series, with limits of detection at a level of $1.0-2.0 \mu \mathrm{g} / \mathrm{L}$ [18].

One of solutions of the problem of water purification of antibiotics lies in the development of methods of the selective extraction of antibiotics from water, including the preconcentration of analytes followed by chromatographic $[19,20]$ or luminescence determination [21]. A combination of adsorption preconcentration with subsequent determination in the solid phase enhances the sensitivity of instrumental methods. The 
determination of tetracycline and its analogs after their solid-phase preconcentration on organopolymers $\left(c_{\min }=0.6 \mu \mathrm{g} / \mathrm{L}\right) \quad[22]$, silicate fibers $\left(c_{\min }=\right.$ $0.022 \mu \mathrm{g} / \mathrm{L}$ ) [23], and hybrid films based on $\mathrm{SiO}_{2}$ modified by polyelectrolytes with solid-phase spectrophotometric or solid-phase luminescence determination in the concentration range $0.266-4.440 \mathrm{mg} / \mathrm{L}$ with the lower boundary of the analytical range for tetracycline 1.33 and $0.267 \mathrm{mg} / \mathrm{L}$, respectively [24, 25], and also on Silasorb 60 silica (for doxycycline, $c_{\min }=$ $0.044 \mathrm{mg} / \mathrm{L}$, analytical range $10^{-7}-10^{-5} \mathrm{M}$ ) [26], silica chemically modified by iminodiacetic acid $\left(c_{\min }=\right.$ $0.5 \mathrm{mg} / \mathrm{mL})$ [27], $\mathrm{Eu}_{2} \mathrm{O}_{3}$ nanoparticles $\left(c_{\min }=\right.$ $8.0 \mu \mathrm{g} / \mathrm{L}$, analytical range $20-1000 \mu \mathrm{g} / \mathrm{L}$ ) [28] was described. In [29], a number of adsorbents, such as silica (C18), pectin, cellulose fibers, and filter paper were tested in the solid-phase luminescence determination of tetracycline in foodstuffs and aqueous solutions. The best reproducibility and sensitivity were reached using silica $\left(c_{\min }=1 \mu \mathrm{g} / \mathrm{L}\right)$. The majority of the above adsorbents does not possess complexing properties with respect to europium(III) ions and, correspondingly, cannot enter the analytical form as the second ligand in the luminescence determination of the antibiotic directly in the adsorbent phase. The introduction of an additional ligand, participating in the transfer of excitation energy as a sensitizer, favors the replacement of water molecules from the inner sphere of the mixed-ligand europium(III) complex with tetracyclines, which significantly increases the intensity of the sensitized luminescence of europium(III) ions and, therefore, the efficiency and reliability of the results of the analysis, particularly in complex systems. This necessitates the development of new solid-phase adsorbents for the selective extraction, preconcentration, and determination of antibiotics.

The aim of this work was the improvement of the characteristics of chemical analytical procedures for the adsorption preconcentration and determination of residual amounts of tetracycline in aqueous solutions, including bottled water, using adsorbents based on chemically modified silica followed by luminescence determination in the solid phase of the adsorbent and directly in the solution.

\section{EXPERIMENTAL}

Reagents. Europium(III) chloride hexahydrate $\left(\mathrm{EuCl}_{3} \cdot 6 \mathrm{H}_{2} \mathrm{O}, 366.41 \mathrm{~g} / \mathrm{mol},>99 \%\right)$ and tetracycline hydrochloride $\left(\mathrm{C}_{22} \mathrm{H}_{24} \mathrm{~N}_{2} \mathrm{O}_{8}, 480.9 \mathrm{~g} / \mathrm{mol},>99 \%\right)$ (Sigma-Aldrich) were used without additional purification. Sodium ( $N$-[(3-trimethoxysilyl)propyl]ethylenediaminetriacetate (ED3A, 45.0\% in water, FluoroChem) and Arsenazo I (Reakhim, analytical grade) were used.

We also used sodium citrate monohydrate (Cit) $\left(\mathrm{Na}_{2} \mathrm{C}_{6} \mathrm{H}_{8} \mathrm{O}_{7} \cdot \mathrm{H}_{2} \mathrm{O}, 210.14 \mathrm{~g} / \mathrm{mol}\right.$, Sigma-Aldrich).
Stock solutions of sodium citrate $\left(1 \times 10^{-3} \mathrm{M}\right)$ were prepared by dissolving precisely weighed portions of the substance in distilled water. Working solutions were prepared by diluting the stock solution immediately before the experiment.

Stock solutions of europium(III) and tetracycline of the concentration $0.01 \mathrm{M}$ were prepared by dissolving precisely weighed portions of substances in water and stored at $4{ }^{\circ} \mathrm{C}$ in a dark place. Solutions of lower concentrations were prepared by diluting the stock solution. All solutions were prepared using Milli-Q (Millipore) water $\left(18 \mathrm{M} \Omega / \mathrm{cm}, \mathrm{pH} 5.6,20^{\circ} \mathrm{C}\right)$.

The required $\mathrm{pH}$ of the solutions was created with a Tris- $\mathrm{HCl}$ buffer solution or an $\mathrm{HCl}$ solution. The Tris- $\mathrm{HCl}$ buffer solution with $\mathrm{pH}$ 7.00-9.00 ( \pm 0.20$)$ was obtained using Tris (hydroxymethyl)aminomethane (Fluka, purity $>99 \%$ ) and hydrochloric acid. The total concentration of the salt in the buffer solution was $0.05 \mathrm{M}$, the corresponding ionic strength of the solution was equal to $0.046 \mathrm{M}$. The $\mathrm{pH}$ of solutions was controlled using a WTW pH-538 $\mathrm{pH}$-meter $( \pm 0.005)$.

We used unmodified silica (Silica gel 60, Merck, 100-200 mesh, $S_{\mathrm{sp}}=500 \mathrm{~m}^{2} / \mathrm{g}$ ), and also silicas with covalently immobilized sulfonic $\left(\mathrm{SiO}_{2} \mathrm{SO}_{3} \mathrm{H}\right)$ and $N$-ethylenediaminetriacetate $\left(\mathrm{SiO}_{2} \mathrm{ED} 3 \mathrm{~A}\right)$ groups. The last adsorbent was synthesized by modified procedure [30] in an aqueous - methanolic reaction mixture $(1: 1)$, using sodium $N$-[(3-trimethoxysilyl)propyl] ethylenediaminetriacetate as a precursor; the concentration of attacted groups according to the data of elemental analysis for nitrogen was $0.28 \mathrm{mmol} / \mathrm{g}$. The $\mathrm{SiO}_{2} \mathrm{SO}_{3} \mathrm{H}$ adsorbent was obtained and characterized by the procedure described earlier [31, 32].

Research methods. Luminescence spectra of mixed-ligand complexes of europium(III) with TC were recorded in the range $600-640 \mathrm{~nm}$ with $\lambda_{\max }=$ $612-615 \mathrm{~nm}$ (transitions ${ }^{5} \mathrm{D}_{0} \rightarrow{ }^{7} \mathrm{~F}_{2}$ ). The analytical signal from solutions was recorded on a Varian Cary Eclipse spectrofluorimeter (Varian, United States) with the accuracy of wavelength measurement $\pm 1.0 \mathrm{~nm}$, slit in the excitation and emission monochromator $10 \mathrm{~nm}$, and scanning rate $120 \mathrm{~nm} / \mathrm{min}$. Emission and excitation spectra of solid samples were recorded on an Edinburgh Instruments FLSP920 spectrofluorimeter (Great Britain).

Absorption spectra of solutions of europium(III) salts were recorded on a dual-beam Thermo Scientific Evolution 600 spectrophotometer in the wavelength region 200-600 nm using 1-cm quartz cells. Diffuse reflection spectra were recorded in an integrating sphere of the diameter $120 \mathrm{~mm}$ using cell for bulk samples with $d=1 \mathrm{~cm}$.

Infrared spectra were recorded on an IR Fouriertransform Spectrometer NEXUS Thermo Nicolet 470 in the range $400-4000 \mathrm{~cm}^{-1}$ in the transmission mode using $\mathrm{KBr}$ pellets $(1: 10)$. 
The equilibrium concentration of europium(III) ions in solutions was determined by spectrophotometry with Arsenazo I at the wavelength $580 \mathrm{~nm}$ [33]. The calibration graph was linear in the range $1 \times 10^{-6}-1 \times$ $10^{-5} \mathrm{M}$ and satisfied the equation $A_{580}=(0.002 \pm$ $0.001)+(0.0301 \pm 0.0004) c_{\mathrm{Eu}}(\mu \mathrm{g} / \mathrm{L}), R^{2}=0.9997$.

The speciation of europium(III) ions in chloride solutions was calculated by the Visual MINTEQ software taking into account stability constants. In calculations we used europium(III) concentrations of $10^{-4}$ and $10^{-6} \mathrm{M}$.

Study of the adsorption of tetracycline on chemically modified silicas. Tetracycline was adsorbed on the studied adsorbents under batch conditions. For this purpose, weighed portions of CMS from 0.05 to $0.20 \mathrm{~g}$ were placed in glass test tubes and stirred with an antibiotic solution $(10 \mathrm{~mL})$ with a mechanical shaker before the attainment of an adsorption equilibrium. Studies were conducted in the $\mathrm{pH}$ range $0.5-8$ within 0-120 min. The time necessary for the attainment of an adsorption equilibrium between the solution and adsorbent was found from kinetic curves obtained by consecutive sampling and determination of the residual amount of TC in the solution after the separation of the solid phase. The initial and equilibrium concentrations of TC in the solution were determined by the luminescence method using a calibration dependence. To construct a calibration graph, we placed $0,0.01$, $0.05,0.1,0.5,1.0,1.5,2.0,2.5,3.0$, and $3.5 \mathrm{~mL}$ of a $2 \times$ $10^{-5} \mathrm{M}$ TC solution into $10-\mathrm{mL}$ flasks. Then $1 \mathrm{~mL}$ of a $1 \times 10^{-3} \mathrm{M}$ solution of sodium citrate, $1 \mathrm{~mL}$ of a 1.0 $\times 10^{-3} \mathrm{M} \mathrm{EuCl}_{3}$ solution, and $5 \mathrm{~mL}$ of a Tris- $\mathrm{HCl}$ buffer solution with $\mathrm{pH} 7.2$ were added to each flask and the contents of the flasks were brought to the mark with distilled (Milli-Q) water and carefully stirred. A dependence on the coordinates $I=f(c)$ was built for the measured luminescence intensity of the obtained solutions.

The desorption of the antibiotic from the adsorbent surface was performed in the batch condition. For this purpose, an adsorbent containing TC was treated with from 2 to $5 \mathrm{~mL}$ of an eluent within $10-20 \mathrm{~min}$. The eluents were 1.0, 0.05, and $0.01 \mathrm{M} \mathrm{HCl}$ and 1.0, 0.05, 0.15 , and $0.015 \mathrm{M} \mathrm{HNO}_{3}$. The concentration of TC in the eluate was determined by the luminescence method. The completeness of TC desorption from the CMS surface was controlled by IR spectrometry.

The adsorption capacity $(A, \mathrm{mmol} / \mathrm{g})$ of adsorbents for TC was determined as follows: $1 \mathrm{~mL}$ of a $1.0 \times 10^{-3} \mathrm{M}$ TC solution and $4 \mathrm{~mL}$ of a Tris- $\mathrm{HCl}$ buffer solution were added to $0.1 \mathrm{~g}$ of an adsorbent with the known concentration of europium(III); the suspension obtained was allowed to stand for $12 \mathrm{~h}$ under continuous stirring at room temperature. Then the solid phase was filtered off, an aliquot portion of the filtrate $(1 \mathrm{~mL})$ was taken, and the equilibrium concentration of the antibiotic was found. The adsorption capacity of the adsorbents $(A, \mathrm{mmol} / \mathrm{g})$ and the recovery of the TC $(R, \%)$ were calculated by the equations $A=\left(c_{0}-c_{\mathrm{e}}\right) V / g$ and $R=\left(c_{0}-c_{\mathrm{e}}\right) / c_{0} \times 100 \%$, where $c_{0}$ and $c_{\mathrm{e}}$ were concentration of TC in the solution before and after adsorption, respectively, $\mathrm{M} ; V$ was total amount of the suspension, $\mathrm{L}$; and $g$ was adsorbent weighed portion, $\mathrm{g}$.

\section{RESULTS AND DISCUSSION}

Choice of silica matrix. To increase in the affinity of the analyte to the inorganic matrix, we used silicas with covalently immobilized sulfonic $\left(\mathrm{SiO}_{2} \mathrm{SO}_{3} \mathrm{H}\right)$ and $N$-ethylenediaminetriacetate $\left(\mathrm{SiO}_{2} \mathrm{ED} 3 \mathrm{~A}\right)$ groups, because N,O-containing reagents form stable complexes with lanthanide ions [34, 35], including the europium(III) ion [36]. In addition, mixed-ligand luminescent complexes of sodium ethylenediaminetetraacetate (complexone III) with europium ions were used for the determination of tetracycline in solutions [16]. In contrast to $\mathrm{SiO}_{2}$ ED3A modified by complexing groups of moderate acidity, the sample of $\mathrm{SiO}_{2} \mathrm{SO}_{3} \mathrm{H}$ contained strongly acid groups and, therefore, possessed cation-exchange properties in a wider range of $\mathrm{pH}$ compared to $\mathrm{SiO}_{2} \mathrm{ED} 3 \mathrm{~A}$. The difference in the nature of the surface layer of the specified silicas may be responsible for the difference in the working ranges of these solid-phase systems and, correspondingly, in their analytical properties.

To increase the sensitivity of the determination of TC, we studied a possibility of its determination on the CMS surface as a complex compound with europium(III). For this purpose, the surfaces of $\mathrm{SiO}_{2} \mathrm{SO}_{3} \mathrm{H}$ and $\mathrm{SiO}_{2}$ ED3A were premodified with europium(III) ions.

Choice of the conditions of europium(III) adsorption on the surface of $\mathrm{SiO}_{2} \mathrm{SO}_{3} \mathrm{H}$ and $\mathrm{SiO}_{2} \mathrm{ED}_{3} \mathrm{~A}$. The main factor affecting the adsorption of metal ions on complexing adsorbents is the acidity of the medium, which determined both the ionic form of the metal and the form of functional analytical groups in the surface adsorbent layer. To obtain CMS samples with a required concentration of europium(III) in the surface layer, we studied the conditions of lanthanide extraction, depending on the acidity of the solution, duration of phase contact, and concentration of metal ions in the solution (Fig. 1).

It was found that europium(III) ions poorly adsorbed on the studied adsorbents $\left(\mathrm{SiO}_{2} \mathrm{ED} 3 \mathrm{~A}\right.$ and $\left.\mathrm{SiO}_{2} \mathrm{SO}_{3} \mathrm{H}\right)$ at $\mathrm{pH} \leq 4$; however, in the $\mathrm{pH}$ range from 6.5 to 7.5 , they were recovered quantitatively (about 99\%). Note that, under experimental conditions, we could not attain the quantitative recovery of europium(III) ions on unmodified silica in the studied $\mathrm{pH}$ range (Fig. 1). Calculations showed that, in neutral and alkaline solutions of the concentration $10^{-4}$ and $10^{-6} \mathrm{M}$, europium(III) occurred mainly as $\mathrm{Eu}^{3+}$ and 


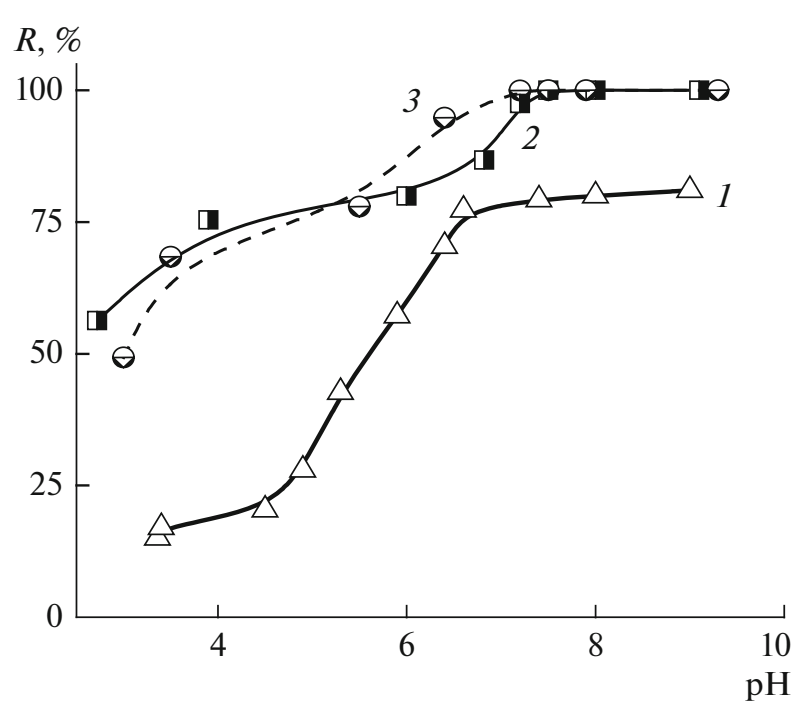

Fig. 1. Dependence of the recovery of $\mathrm{Eu}^{3+}$ ions on the acidity of the medium: $1, \mathrm{SiO}_{2} ; 2, \quad \mathrm{SiO}_{2} \mathrm{SO}_{3} \mathrm{H}$; 3, $\mathrm{SiO}_{2} \mathrm{ED} 3 \mathrm{~A} ; c_{\mathrm{EuCl}_{3}}=1 \times 10^{-4} \mathrm{M}, g=0.1 \mathrm{~g}$.

$\mathrm{EuOH}^{2+}$ (total concentration of about $98 \mathrm{~mol} \%$ ) and the concentration of $\mathrm{EuCl}^{2+}$ did not exceed $1 \mathrm{~mol} \%$ even at a 100 -fold dilution of the solution (Fig. 2). At higher $\mathrm{pH}$ values, the complexes decomposed because of the partial hydrolysis of lanthanide salts and the predominance of hydroxo forms, such as $\mathrm{EuOH}^{2+}$, etc. (Fig. 2), which agrees with the data [37].

It was found that adsorption equilibrium in the system was attained within 10 min for unmodified silica and no more than $5 \mathrm{~min}$ for samples of $\mathrm{SiO}_{2} \mathrm{SO}_{3} \mathrm{H}$ and $\mathrm{SiO}_{2}$ ED3A. According to adsorption isotherms of $\mathrm{Eu}^{3+}$ ions on the studied adsorbents, the maximum values of adsorption capacity under batch conditions were $0.15,0.14$, and $0.05 \mathrm{mmol} / \mathrm{g}$ for $\mathrm{SiO}_{2} \mathrm{SO}_{3} \mathrm{H}$, $\mathrm{SiO}_{2} \mathrm{ED} 3 \mathrm{~A}$, and $\mathrm{SiO}_{2}$, respectively, which is optimum for the luminescence determination of TC [27].

For the luminescence determination of tetracycline, we used CMS adsorbents bearing complexing europium(III) ions in the surface layer, synthesized under optimum conditions.

Optimization of analytical signal in the luminescence determination of tetracycline. The excitation spectrum of adsorbents bearing europium(III) complexes with attached groups and tetracyclines in a surface layer exhibited absorption bands at 320 and $410 \mathrm{~nm}$. Under identical measurement conditions, the luminescence intensity of the Eu-TC complex was 2-4 times higher at $\lambda_{\max }=410 \mathrm{~nm}$.

It is known [15] that, in the solution, the luminescence intensity of europium(III) compounds considerably increases in the formation of mixed-ligand complexes in the presence of donor-active organic ligands, such as hydroxycarbonic acids [15], cationic

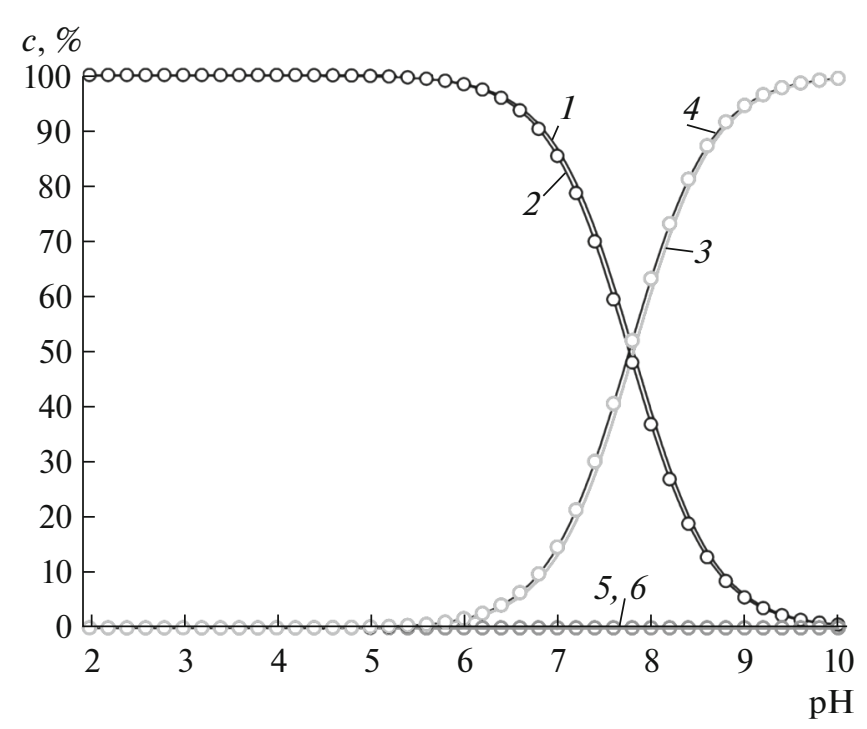

Fig. 2. Diagrams of the distribution of equilibrium forms in $\mathrm{EuCl}_{3}$ solutions of different concentrations depending on the $\mathrm{pH}$ of the solution: $1,10^{-4} \mathrm{M} \mathrm{Eu}^{3+} ; 2,10^{-6} \mathrm{Eu}^{3+}$; $3,10^{-4} \mathrm{M} \mathrm{EuOH}^{2+} ; 4,10^{-6} \mathrm{M} \mathrm{EuOH}^{2+} ; 5,10^{-4} \mathrm{M}$ $\mathrm{EuCl}^{2+} ; 6,10^{-6} \mathrm{M} \mathrm{EuCl}^{2+}$.

and nonionic surfactants $[15,16,26]$, hydrogen peroxide [15], and also some inorganic salts [38]. The luminescence intensity of the Eu-TC system increased in presence citrate ions (Fig. 3), and the maximum luminescence intensity of Eu-TC system was observed at $c_{\mathrm{Cit}}=c_{\mathrm{Eu}}=1 \times 10^{-4} \mathrm{M}$ (Fig. 3). The maximum luminescence intensity in the system was attained within $30 \mathrm{~s}$ after mixing the solutions and remained constant for a long time, at least $3 \mathrm{~h}$. Note that an increase in the concentration of citrate ions to $0.01 \mathrm{M}$ resulted in the disappearance of the band at $615 \mathrm{~nm}\left({ }^{5} \mathrm{D}_{0} \rightarrow{ }^{7} \mathrm{~F}_{2}\right)$ in the luminescence spectrum, which was due to the interference of citrate ions with the formation of mixed-ligand $\mathrm{Eu}^{3+}$ complexes including TC.

The next luminescence measurements were performed in the presence of citrate ions in the concentration $1 \times 10^{-4} \mathrm{M}$.

Optimization of the conditions of tetracycline preconcentration on chemically modified silicas. We studied the adsorption of tetracycline on the chosen adsorbents depending on the time of phase contact, $\mathrm{pH}$ of the solution, and adsorbent nature (Figs. 4, 5).

The recoveries of tetracycline on the studied adsorbents strongly differed in the studied $\mathrm{pH}$ range (Fig. 4). The efficiency of the extraction of the antibiotic decreased with an increase in the acidity of solutions, except for the case of the initial $\mathrm{SiO}_{2} \mathrm{SO}_{3} \mathrm{H}$ adsorbent, for which we observed almost quantitative extraction of the analyte at $\mathrm{pH} 2$. On unmodified $\mathrm{SiO}_{2}$, tetracycline virtually did not adsorb in the whole studied acidity range (no more than $20 \%$ ). The opti- 


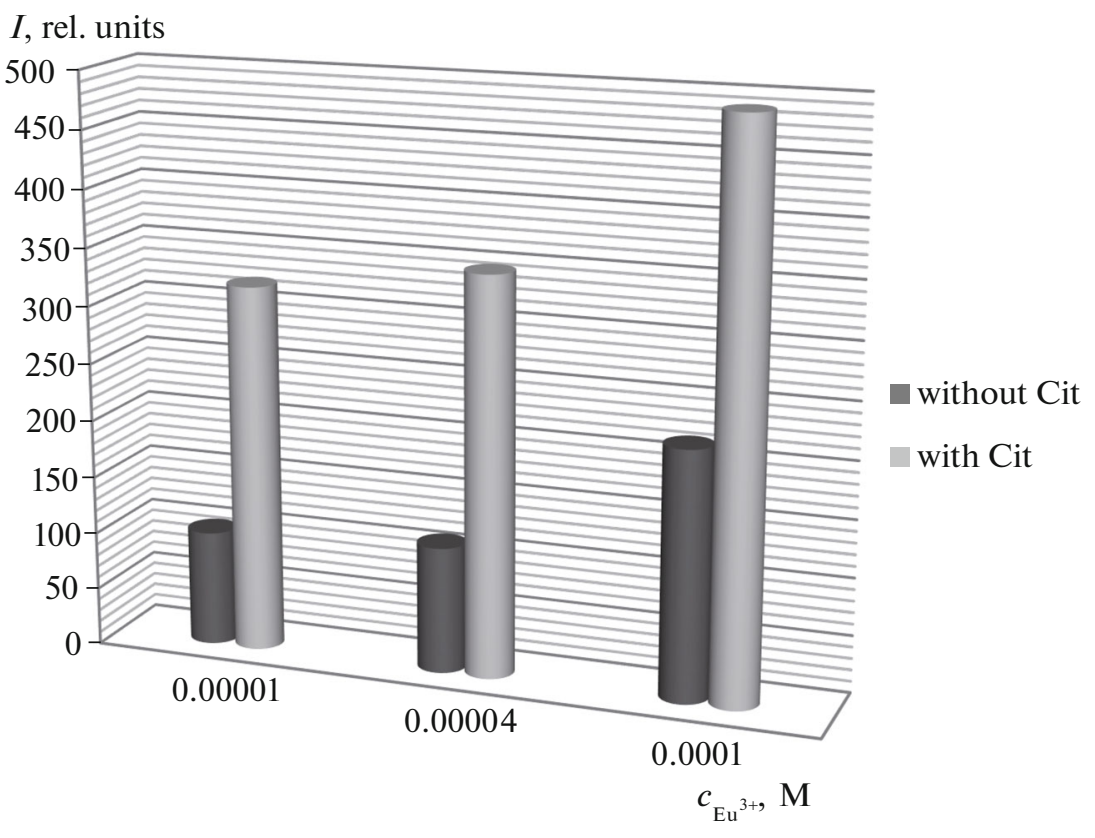

Fig. 3. Luminescence intensity of the $\mathrm{Eu}-\mathrm{TC}$ complex as a function of the concentration of $\mathrm{Eu}^{3+}$ ions in the presence and absence of citrate ions. $c_{\mathrm{Cit}}=1 \times 10^{-4} \mathrm{M}, c_{\mathrm{TC}}=1 \times 10^{-6} \mathrm{M}, \mathrm{pH} \mathrm{7.20,} \lambda_{\mathrm{ex}}=410 \mathrm{~nm}$.

mum acidity ranges for the extraction of the analyte on adsorbents containing europium(III) ions $\left(\mathrm{SiO}_{2} \mathrm{SO}_{3} \mathrm{HEu}\right.$ and $\left.\mathrm{SiO}_{2} \mathrm{ED} 3 \mathrm{AEu}\right)$ virtually coincided and were pH 6.5-8.0 (Fig. 4). In system $\mathrm{SiO}_{2}$ Eu based on an unmodified silica, we could not reach quantitative adsorption and the maximum recovery of tetracycline was $69 \%$.

The effect of some macrocomponents usually present in drinking water on the completeness of TC extraction was studied. It was shown that, at $\mathrm{pH} 7.2-$

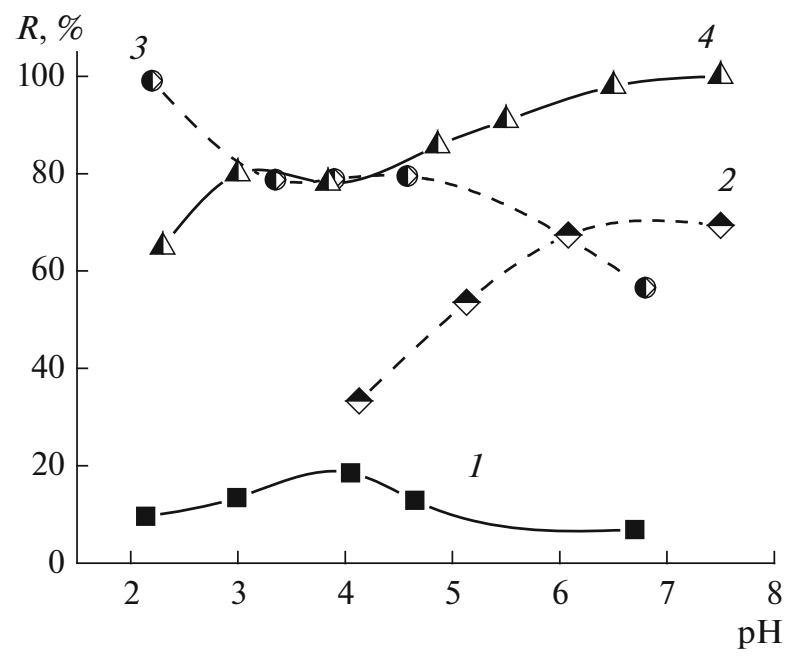

Fig. 4. $\mathrm{pH}$ dependence of the recovery of $\mathrm{TC}$ on adsorbents (1) $\mathrm{SiO}_{2}$, (2) $\mathrm{SiO}_{2} \mathrm{Eu}$, (3) $\mathrm{SiO}_{2} \mathrm{SO}_{3} \mathrm{H}$, and (4) $\mathrm{SiO}_{2} \mathrm{SO}_{3} \mathrm{HEu}$.
7.5, 5-fold amounts of $\mathrm{Ca}^{2+}$ ions had no noticeable effect on the analyte extraction, in contrast to equimolar amounts of iron(III).

Tetracycline $\left(\mathrm{p} K_{\mathrm{a}_{1}}=3.3, \mathrm{p} K_{\mathrm{a}_{2}}=7.7, \mathrm{p} K_{\mathrm{a}_{3}}=9.7\right.$ [39]) in solutions occurs in four species [40]: cationic $\mathrm{TCH}^{+}$(at $\mathrm{pH}<\mathrm{p} K_{\mathrm{a}_{1}}$ ), anionic $\mathrm{TCH}^{-}$and $\mathrm{TC}^{2-}$ (at $\mathrm{pH}>\mathrm{p} K_{\mathrm{a}_{2}}$ and $\mathrm{pH}>\mathrm{p} K_{\mathrm{a}_{3}}$, respectively), and neutral

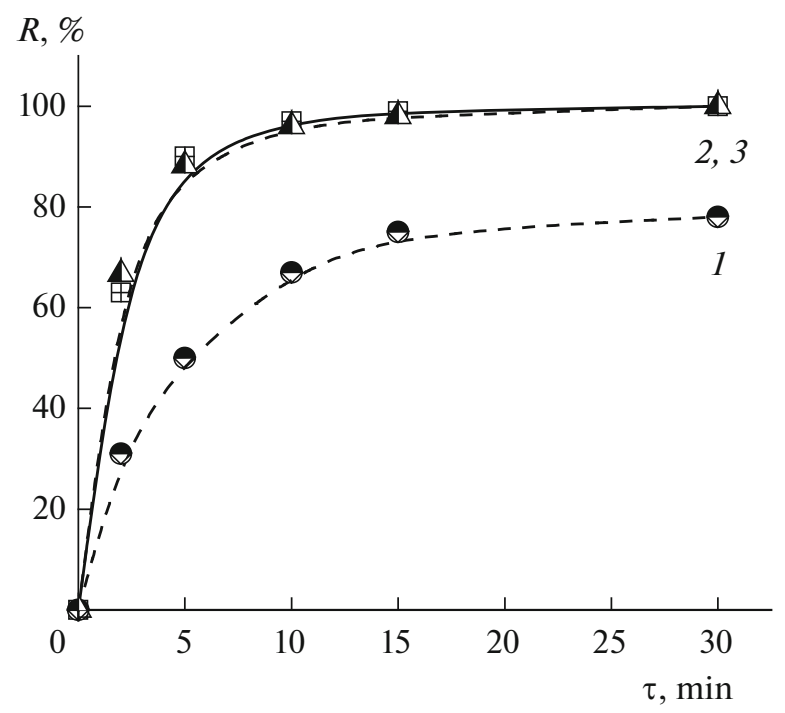

Fig. 5. Dependence of the recovery of TC on adsorbents (1) $\mathrm{SiO}_{2} \mathrm{Eu}$, (2) $\mathrm{SiO}_{2} \mathrm{ED} 3 \mathrm{AEu}$, (3) $\mathrm{SiO}_{2} \mathrm{SO}_{3} \mathrm{HEu}$ on the time of phase contact. $m=0.1, V_{\text {total }}=10 \mathrm{~mL}, c_{\mathrm{TC}}=2 \times$ $10^{-5} \mathrm{M}, \mathrm{pH} 7.2$. 
or zwitter-ionic TC form $\left(\mathrm{p} K_{\mathrm{a}_{1}}<\mathrm{pH}<\mathrm{p} K_{\mathrm{a}_{2}}\right)$. The behavior of the $\mathrm{pH}$ dependence of recovery (Fig. 4) suggests that, on the $\mathrm{SiO}_{2} \mathrm{SO}_{3} \mathrm{HEu}$ surface, as on the $\mathrm{SiO}_{2} \mathrm{ED} 3 \mathrm{AEu}$ surface, TC was adsorbed mainly in the range of the predominance of the molecular and anionic species. The maximum adsorption was observed in the range $\mathrm{p} K_{\mathrm{a}_{1}}<\mathrm{pH}<\mathrm{p} K_{\mathrm{a}_{2}}$. At the same time, for a sample of $\mathrm{SiO}_{2} \mathrm{SO}_{3} \mathrm{H}$ containing no com- plexing europium(III) ions, the region of the quantitative exraction of the antibiotic shifted to the acid medium (Fig. 4), i.e., to the conditions under which the tetracycline molecule is in the protonated cationic form $\left(\mathrm{TCH}^{+}\right)$[40] and, most likely, the analyte interacts with strongly acid groups of the alkylsulfonic acid covalently immobilized on the $\mathrm{SiO}_{2}$ surface mainly through electrostatic interactions according to the following scheme:<smiles>C[NH+](C)[C@H]1C(O)=C(C(N)=O)C(=O)[C@@]2(O)C(O)=C3C(=O)c4c(O)cccc4[C@@](C)(O)C3CC12</smiles>

It was found that, with an increase in the time of adsorption, the recovery of TC monotonously increased and achieved a plateau; the maximum recovery of the analyte was attained on the surface of modified adsorbents within $10 \mathrm{~min}$ (Fig. 5). At the same time, the recovery of the analyte by the systems based on CMS was much higher than by native silica under the chosen optimum conditions.

The affinity of TC to adsorbents bearing complexing $\mathrm{Eu}^{3+}$ ions was found from adsorption isotherms under optimum conditions. To take into account the effect of the silica matrix, we studied adsorption isotherms of both modified and native silica (Fig. 6). In all cases, the isotherms belonged to the $\mathrm{H} 1$ type, which points to the high affinity of the adsorbate to the



Fig. 6. Adsorption isotherms of TC on the surface of adsorbents (1) $\mathrm{SiO}_{2} \mathrm{Eu}$, (2) $\mathrm{SiO}_{2} \mathrm{SO}_{3} \mathrm{HEu}$, and (3) $\mathrm{SiO}_{2} \mathrm{ED} 3 \mathrm{AEu}$. $V=10 \mathrm{~mL}, g=0.05 \mathrm{~g}, \mathrm{pH}$ 7.2.

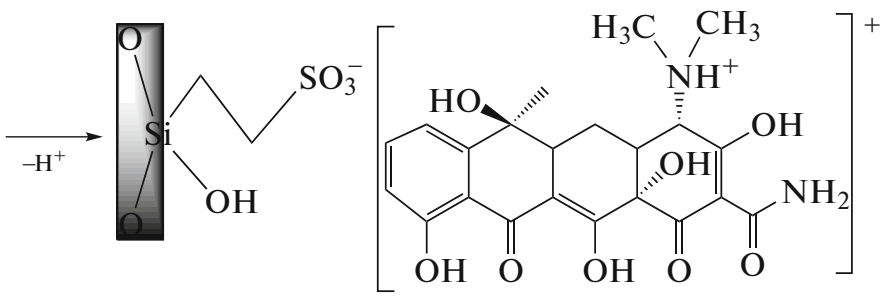

adsorbents (Fig. 6). The maximum adsorption of TC in the Henry region on $\mathrm{SiO}_{2} \mathrm{SO}_{3} \mathrm{HEu}$ and $\mathrm{SiO}_{2} \mathrm{ED} 3 \mathrm{AEu}$ was 0.09 and $0.07 \mathrm{mmol} / \mathrm{g}$, respectively. At the same time, the modification of silicas by acid groups increased adsorption capacity three- to fourfold (Fig. 6). A comparison of adsorption isotherms showed that the maximum capacity to tetracycline $(0.14 \mathrm{mmol} / \mathrm{g})$ was found for the $\mathrm{SiO}_{2} \mathrm{SO}_{3} \mathrm{HEu}$ system; it corresponds to the ratio of $\mathrm{Eu}^{3+}$ ions immobilized on the surface of CMS and TC $\approx 1: 1$.

The adsorption of tetracycline from solutions was accompanied by a change in the adsorbent color. After extraction from solutions, the adsorbents became yellow or light yellow, and color shade depended on the analyte concentration and adsorbent nature. The best contrast was observed for the $\mathrm{SiO}_{2} \mathrm{SO}_{3} \mathrm{H}$ adsorbent after its contact with TC in an acid medium $(\mathrm{pH} 2$, Fig. 3a). In the near UV region, then electronic spectra of diffuse reflection of a sample of $\mathrm{SiO}_{2} \mathrm{SO}_{3} \mathrm{H}-\mathrm{TC}$ exhibited an intense absorption band at $380 \mathrm{~nm}$, which corresponded to the absorption of the tetracycline molecule [16, 24]. In IR spectra of the adsorbent, we observed bands at 1550 and $1450 \mathrm{~cm}^{-1}$, assigned to $\mathrm{v}\left(\mathrm{C}_{\mathrm{Ar}}-\mathrm{C}_{\mathrm{Ar}}\right)$ of the system of aromatic rings of the tetracycline, and also a characteristic intense band of its carbonyl group $v_{\text {as }}(C=O)$ at $1654 \mathrm{~cm}^{-1}$.

Based on the data obtained, we developed a procedure for the solid-phase spectrophotometric determination of tetracycline in the concentration range 10$100 \mathrm{mM}$. The intense bright yellow color of the adsorbate on the surface of $\mathrm{SiO}_{2} \mathrm{SO}_{3} \mathrm{H}$ suggests that tetracycline can also be determined by a visual test method.

Luminescence determination of tetracycline with preconcentration on chemically modified silicas. Two versions of a procedure for the luminescence determination of TC were proposed: in solution after elution from the adsorbent surface (version 1) and directly in the solid phase of the adsorbent (version 2). 
Version 1. Tetracycline was desorbed from the adsorbent surface in an acid medium and determined in solution by the luminescence method (Fig. 7). We studied $\mathrm{HCl}$ and $\mathrm{HNO}_{3}$ of different concentrations as eluents. $\mathrm{HNO}_{3}$ of $\mathrm{pH} 1.0$ appeared the optimum eluent for the extraction of TC from the surface of $\mathrm{SiO}_{2} \mathrm{ED} 3 \mathrm{AEu}-\mathrm{TC}$. The use of $\mathrm{HCl}$ and $\mathrm{HNO}_{3}$ for the $\mathrm{SiO}_{2} \mathrm{SO}_{3} \mathrm{HEu}-\mathrm{TC}$ system did not allow the complete elution of the analyte from the adsorbent surface at this $\mathrm{pH}$ value. This is, possibly, explained by the decomposition of the europium(III) complex with TC, followed by the interaction of TC with the $\mathrm{SiO}_{2} \mathrm{SO}_{3} \mathrm{H}$ adsorbent (see scheme). Quantitative desorption from the surface of $\mathrm{SiO}_{2} \mathrm{SO}_{3} \mathrm{HEu}-\mathrm{TC}$ was attained only with $0.5 \mathrm{M} \mathrm{HNO}_{3}$. Using mineral acid solutions of lower concentrations, we could not elute tetracycline from the surface of this CMS.

To construct a calibration graph, we prepared a series of TC solutions containing citrate and $\mathrm{Eu}^{3+}$ ions. The calibration dependence was described by the equation: $I=(2.994 \pm 0.2117)+(0.93245 \pm$ $0.42761) \times c_{\mathrm{TC}}(\mu \mathrm{M})\left(r^{2}=0.99857\right)$ in the range of $1 \times$ $10^{-7}-1 \times 10^{-5} \mathrm{M}$, the limit of detection was $5.0 \mathrm{nM}$ (estimated by the $3 s$-test).

The effect of the ratio of the solution volume to the adsorbent weight on the recovery of the antibiotic was studied on an example of the $\mathrm{SiO}_{2} \mathrm{ED} 3 \mathrm{AEu}$ system (Table 1). Under optimum conditions, the maximum partition coefficient of TC $(D, \mathrm{~mL} / \mathrm{g})$ was attained at $V: m=500$; it was $7.5 \times 10^{4} \mathrm{~mL} / \mathrm{g}($ at $\log D=4.9)$. At a 20 -fold increase in the volume of the solution with the amount of the adsorbent remained the same, partition coefficient decreased approximately fivefold. At an increase in the ratio $V: m$, recovery changed slightly, preconcentration factors were $12-150$, and the values of partition coefficients remained high (Table 1), which allowed the use of $\mathrm{SiO}_{2} \mathrm{ED} 3 \mathrm{AEu}$ as an adsorbent for the adsorption preconcentration of tetracycline from dilute solutions.

It was shown that, in the heterogeneous system CMS-water, the time of adsorbent sedimentation and separation depends on the weighed portion, size of $\mathrm{SiO}_{2}$ particles, and volume of the solution. Thus, for

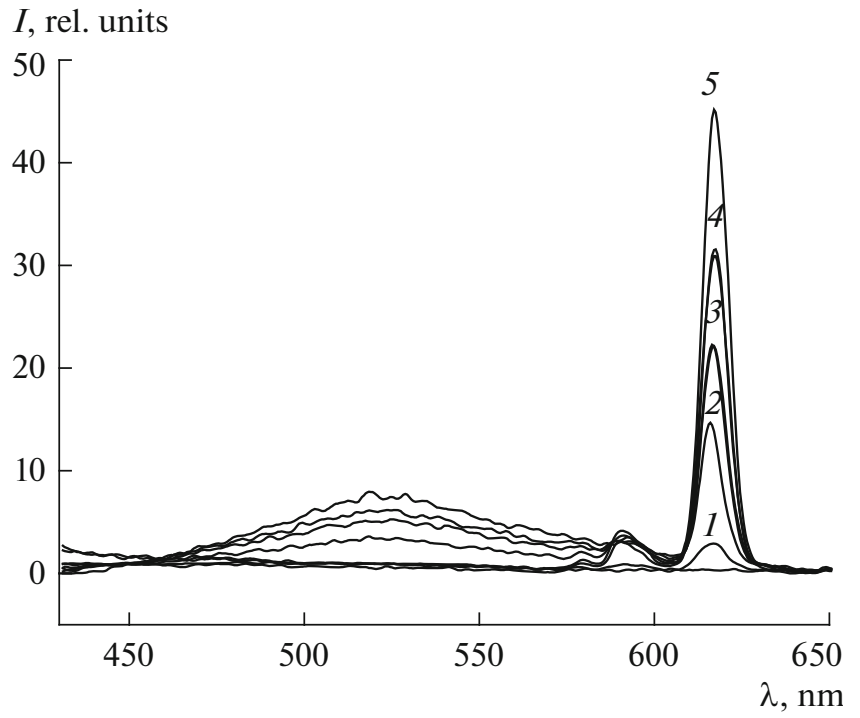

Fig. 7. Luminescence spectra of TC solutions $\left(1 \times 10^{-7} \leq\right.$ $\left.c_{\mathrm{TC}} \leq 1 \times 10^{-6} \mathrm{M}\right)$ at $\mathrm{pH} 7.20$ after desorption from the $\mathrm{SiO}_{2} \mathrm{ED} 3 \mathrm{AEu}$ surface. $c_{\mathrm{Eu}}=c_{\mathrm{Cit}}=1 \times 10^{-4} \mathrm{M}, \lambda_{\mathrm{ex}}=$ $410 \mathrm{~nm}, V_{\text {eluent }}=2 \mathrm{~mL}$.

$100 \mathrm{~mL}$ of a suspension containing $0.05 \mathrm{~g}$ of the adsorbent, the complete sedimentation of particles was reached within $32 \mathrm{~s}$, and with an increase in the volume of the suspension to $500 \mathrm{~mL}$, the time of sedimentation increased to $45 \mathrm{~s}$. An increase in the weighed portion of the adsorbent to $0.1 \mathrm{~g}$ increased sedimentation time, on the average, by $30 \%$.

From the curves of luminescence quenching we calculated lifetimes $(\tau)$ of $\mathrm{SiO}_{2} \mathrm{SO}_{3} \mathrm{HEu}-\mathrm{TC}$ and $\mathrm{SiO}_{2}$ ED3AEu-TC complexes, which were 38 and $54 \mu \mathrm{s}$, respectively, pointing to the reduction of radiationless excitation energy in the europium(III) complex at polydentate coordination with ethylenediaminetriacetate groups attached to the $\mathrm{SiO}_{2}$ surface, which led to the enhancement of the sensitized luminescence of europium(III) ions.

Version 2. Solid-phase luminescence determination of $T C$ using systems based on CMS. The luminescence spectra of $\mathrm{SiO}_{2} \mathrm{SO}_{3} \mathrm{HEu}$ and $\mathrm{SiO}_{2} \mathrm{ED} 3 \mathrm{AEu}$ systems

Table 1. Dependence of recovery $(R)$ and partition $(D)$ and concentration $(K)$ coefficients of tetracycline by the $\mathrm{SiO}_{2} \mathrm{ED} 3 \mathrm{AEu}$ system on the ratio of the volume of the solution to the adsorbent weight $\left(\mathrm{pH} 7.2\right.$, time $10 \mathrm{~min}, V_{\mathrm{el}}=2 \mathrm{~mL}$, $\left.t_{n=4, P=0.95}=3.18\right)$

\begin{tabular}{r|r|c|c|c|c|c}
\hline$V, \mathrm{~mL}$ & $V: m$ & Found TC, $\mu \mathrm{g}$ & $R, \%$ & $D, \mathrm{~mL} / \mathrm{g}$ & $\log D$ & $K$ \\
\hline 25 & 500 & $1.49 \pm 0.02$ & 99.3 & 74500 & 4.9 & 12 \\
50 & 1000 & $1.47 \pm 0.03$ & 98.0 & 49000 & 4.7 & 24 \\
100 & 2000 & $1.43 \pm 0.02$ & 95.3 & 40857 & 4.6 & 48 \\
250 & 5000 & $1.25 \pm 0.05$ & 83.3 & 25000 & 4.4 & 104 \\
500 & 10000 & $0.90 \pm 0.04$ & 60.0 & 15000 & 4.2 & 150 \\
\hline
\end{tabular}

Note: adsorbent weight $m=0.05 \mathrm{~g}$, added $1.50 \mu \mathrm{g}$ TC. 




Fig. 8. Luminescence spectra of the $\mathrm{SiO}_{2} \mathrm{SO}_{3} \mathrm{HEu}$ system after contact with TC solutions of different concentrations $\left(0.8 \leq c_{\mathrm{TC}} \leq 20.0 \mathrm{mmol} / \mathrm{g}\right) . \mathrm{pH} 7.20, \lambda_{\mathrm{ex}}=410 \mathrm{~nm}$.

after contact with a TC solution exhibited a maximum at $615 \mathrm{~nm}$ (Fig. 8). According to the published data, it corresponds to the formation of mixed-ligand complexes on the surface of a silica matrix [41]. The luminescence intensity of systems based on CMS treated with a TC solution increased linearly with the concentration of the analyte in the adsorbent phase (Fig. 8), similarly to aqueous solutions of the antibiotic (Fig. 7) [17]. This fact was used as a basis for procedures of its solid-phase luminescence determination (Table 2).

The system $\mathrm{SiO}_{2} \mathrm{ED} 3 \mathrm{AEu}$ in the determination of TC is superior in sensitivity and characterized by a wider linearity range in comparison to the systems $\mathrm{SiO}_{2} \mathrm{SO}_{3} \mathrm{HEu}$ and $\mathrm{SiO}_{2} \mathrm{Eu}$ (Table 2). Therefore, the application of CMS with immobilized ethylenediaminetriacetate groups capable of forming chelates ensures a threefold increase in the sensitivity of the solid-phase luminescence determination of tetracycline in comparison with the system based on $\mathrm{SiO}_{2} \mathrm{SO}_{3} \mathrm{HEu}$. The procedure for the determination of TC using $\mathrm{SiO}_{2} \mathrm{ED} 3 \mathrm{AEu}$ is 70 times more sensitive and selective in comparison with the systems based on unmodified $\mathrm{SiO}_{2}$.

Determination of trace amounts of tetracycline in bottled water using chemically modified silicas. Under the found conditions of the adsorption preconcentration of tetracycline, we proposed a procedure for its solid-phase luminescence determination in water using CMS.

Fifteen milliliters of a Tris- $\mathrm{HCl}$ buffer mixture of $\mathrm{pH} 7.4$ (to create $\mathrm{pH}$ 7.2) and $0.1 \mathrm{~g}$ of an adsorbent modified by europium(III) ions $\left(\mathrm{SiO}_{2} \mathrm{SO}_{3} \mathrm{HEu}\right.$ or $\mathrm{SiO}_{2} \mathrm{ED}_{3} \mathrm{AEu}$ ) are added to $150 \mathrm{~mL}$ of water. The suspension obtained is stirred on a mechanical shaker within $10 \mathrm{~min}$. After adsorption, the solid phase is filtered off and dried in air. The concentration of TC is determined directly in the solid phase of the adsorbent by the luminescence method (at $\lambda_{\mathrm{ex}}=410 \mathrm{~nm}$ and $\lambda_{\mathrm{em}}=615 \mathrm{~nm}$ ) using a calibration graph. The accuracy of the procedure of the quantitative determination of tetracycline in bottled water was checked by the added-found method on model solutions and samples of bottled water (Table 3 ).

The data obtained indicate that the developed procedure is characterized by satisfactory accuracy and reproducibility, is simple, and can be used for the determination of tetracycline. The reproducibility of the results of the solid-phase luminescence determination of tetracycline in water using the $\mathrm{SiO}_{2} \mathrm{ED} 3 \mathrm{AEu}$ system is higher than that using the $\mathrm{SiO}_{2} \mathrm{SO}_{3} \mathrm{HEu}$ system (Table 3). After the adsorption of TC, the adsorbents retained their chemical analytical properties within two weeks if the conditions required for the storage of tetracycline were met. The developed procedure for the determination of TC is several times more sensitive than similar procedures known up to date $[24,29]$.

$$
* * *
$$

Therefore, the ability of cation-exchange and chelating CMS with complexing $\mathrm{Eu}^{3+}$ ions to adsorb tetracycline in different concentrations opens a possibility of using such adsorbents for the extraction and preconcentration of residual amounts of tetracycline from aqueous solutions, including bottled water. The use of

Table 2. Performance characteristics of the procedure for the solid-phase luminescence determination of tetracycline using systems based on chemically modified silicas

\begin{tabular}{|c|c|c|c|c|c|}
\hline \multirow{2}{*}{ System } & \multicolumn{2}{|c|}{$\begin{array}{l}\text { Parameters of regression equation } \\
I=(a \pm \Delta a)+(b \pm \Delta b) c_{\mathrm{TC}}(\mu \mathrm{M})\end{array}$} & \multirow{2}{*}{$\begin{array}{l}\text { Linearity } \\
\text { range, } \mathrm{M}\end{array}$} & \multirow[t]{2}{*}{$r^{2}$} & \multirow{2}{*}{$c_{\min }, \mathrm{nM}$} \\
\hline & $a \pm \Delta a$ & $b \pm \Delta b$ & & & \\
\hline $\mathrm{SiO}_{2} \mathrm{Eu}$ & $50.7 \pm 0.9$ & $48 \pm 5$ & $10^{-7}-10^{-5}$ & 0.9896 & 56.7 \\
\hline $\mathrm{SiO}_{2} \mathrm{SO}_{3} \mathrm{HEu}$ & $52.07 \pm 0.06$ & $70 \pm 3$ & $10^{-9}-10^{-4}$ & 0.9972 & 2.6 \\
\hline $\mathrm{SiO}_{2} \mathrm{ED} 3 \mathrm{AEu}$ & $52.06 \pm 0.05$ & $181.0 \pm 0.4$ & $7.7 \times 10^{-9}-1.0 \times 10^{-5}$ & 0.9993 & 0.8 \\
\hline
\end{tabular}


Table 3. Results of solid-phase luminescence determination of tetracycline $\left(c_{\mathrm{TC}}, \mathrm{mg} / \mathrm{L}\right)$ in model solutions and samples of bottled water using systems based on chemically modified silicas (conditions: $g=0.05 \mathrm{~g}, V=250 \mathrm{~mL}$, $\mathrm{pH} \mathrm{7.2,} \mathrm{time} 10 \mathrm{~min}$, $t_{n=4, P=0.95}=3.18$ )

\begin{tabular}{l|c|c|c|c|c}
\hline \multirow{2}{*}{ Test sample } & \multirow{2}{*}{ Added } & \multicolumn{2}{|c|}{$\mathrm{SiO}_{2} \mathrm{ED} 3 \mathrm{AEu}$} & \multicolumn{2}{c}{$\mathrm{SiO}_{2} \mathrm{SO}_{3} \mathrm{HEu}$} \\
\cline { 2 - 6 } & & found, $\bar{X} \pm \Delta X$ & $\mathrm{RSD}, \%$ & found, $\bar{X} \pm \Delta X$ & $\mathrm{RSD}, \%$ \\
\hline Model solution & 0.1 & $0.08 \pm 0.02$ & 2 & $0.09 \pm 0.01$ & 1 \\
& 0.5 & $0.43 \pm 0.06$ & 4 & $0.46 \pm 0.04$ & 2 \\
Alyaska bottled & - & $0.03 \pm 0.02$ & 2 & $0.04 \pm 0.01$ & 1 \\
water, Ukraune & 0.1 & $0.15 \pm 0.03$ & 2 & $0.14 \pm 0.01$ & 1 \\
\hline
\end{tabular}

Note. Model solution is distilled water containing the antibacterial preparation.

selective CMS is also promising for the solid-phase luminescence determination of antibacterial preparations of the tetracycline series in more complex objects.

\section{ACKNOWLEDGMENTS}

This work was supported by the EU program FP7PEOPLE-2009-IRSES, project no. 247603.

\section{REFERENCES}

1. Al-Turk, I.M. and Diab, A.M., J. Int. Environ. Appl. Sci., 2009, vol. 4, no. 2, p. 214.

2. Falcone-Dias, M.F., Vaz-Moreira, I., and Manaia, C.M., Water Res., 2012, vol. 46, no. 11, p. 3612 .

3. Kümmerer, K., Chemosphere, 2009, vol. 75, p. 417.

4. Kümmerer, K., Chemosphere, 2009, vol. 75, p. 435.

5. Hexing, W., Na, W., Bin, W., Qi, Zh., Hong, F., Chaowei, F., Chuanxi, T., Feng, J., Ying, Zh., Yue, Ch., and Jiang, Q., Environ. Sci. Technol., 2016, vol. 50, no. 5, p. 2692.

6. Calamari, D., Zuccato, E., Castiglioni, S., Bagnati, R., and Fanelli, R., Environ. Sci. Technol., 2003, vol. 37, p. 1241.

7. Farber, H., Hyg. Med., 2002, vol. 27, p. 35.

8. Kolpin, D.W., Furlong, E.T., Meyer, M.T., Thurman, E.M., Zaugg, S.D., Barber, L.B., and Buxton, H.T., Environ. Sci. Technol., 2002, vol. 36, p. 1202.

9. Dayan, A.D., Vet. Microbiol., 1993, vol. 35, p. 213.

10. Massa, S., Petruccioli, M., Fanelli, M., and Gori, L., Microbiol. Res., 1995, vol. 150, no. 4, p. 403.

11. LabMoloko. http://labmoloko.ru/?mcat $=316 \&$ rec $=$ 16907114. Cited August 10, 2016.

12. Loetanantawong, B., Suracheep, C., Somasundrum, M., and Surareungchai, W., Anal. Chem., 2004, vol. 76, p. 2266.

13. Pena, A., Pelantova, N., Lino, C.M., Silveira, M.N., and Solich, P., J. Agric. Food Chem., 2005, vol. 53, p. 3784 .

14. Cinquina, A.L., Longo, F., Anastasi, G., Giannetti, L., and Cozzani, R., J. Chromatogr. A, 2003, vol. 987, nos. 1-2, p. 227.
15. Vityukova, E.O., Egorova, A.V., Bel'tyukova, S.V., and Malinka, E.V., Vestn. Odesskogo Nats. Univ., 2004, vol. 9, no. 6, p. 97.

16. Arnaud, N. and Georges, J., Analyst, 2001, vol. 126, p. 694.

17. Chen, G., Li, Q., Liu, G., Qin, F., and Du, Y., in Physical Methods in Food Chemistry, Tunick, M.H. and Onwulata, C.I., Eds., Wyndmoor, PA: Am. Chem. Soc., 2013, ch. 4, p. 49.

18. Feng, P., Li, Y.F., and Huang, Zh.C., Anal. Chim. Acta, 2001, vol. 442, no. 1, p. 89.

19. Tlili, I., Caria, G., Ouddane, B., Ghorbel-Abid, I., Ternane, R., Trabelsi-Ayadi, M., and Net, S., Sci. Total Environ., 2016, vols. 563-564, p. 424.

20. Cheng, W., Jiang, L., Lu, N., Ma, L., Sun, X., Luo, Y., Lin, K., and Cui, C., Anal. Methods, 2015, vol. 7, no. 5, p. 1777.

21. Liu, L., Chen, G., and Fishman, M.L., Anal. Chim. Acta, 2005, vol. 528, no. 2, p. 261.

22. Udalova, A.Yu., Dmitrienko, S.G., Natchuk, S.V., Apyari, V.V., and Zolotov, Yu.A., J. Anal. Chem., 2015, vol. 70, no. 3, p. 292.

23. Chi-Lap, Kuong, Yu, T., and Chen, Y., Anal. Bioanal. Chem., 2009, vol. 395, p. 1433.

24. Motorina, A.S., Kolesnik, D.L., and Tananaiko, O.Yu., Ukr. Khim. Zhurn., 2010, vol. 76, no. 12 , p. 113.

25. Motorina, A., Tananaiko, O., Kozytska, I., Raks, V., Badía, R., Díaz-Garcia, M.E., and Zaitsev, V.N., Sens. Actuators, B, 2014, vol. 200, no. 1, p. 198.

26. Parashchenko, I.I., Smirnova, T.D., Shtykov, S.N., Kochubei, V.I., and Zhukova, N.N., J. Anal. Chem., 2013, vol. 68, no. 2, p. 112.

27. Voronina, R.D. and Zorov, N.B., J. Anal. Chem., 2007, vol. 62 , no. 3, p. 206.

28. Aguilar-Vazquez, L., Aguilar-Caballos, M.P., and Gomez-Hens, A., Talanta, 2014, vol. 119, no. 6, p. 111.

29. Liu, L., Chen, G., and Fishman, M.L., Anal. Chim. Acta, 2005, vol. 528, no. 1, p. 261.

30. Ohshima, K., Watanabe, H., and Haraguchi, K., Anal. Sci., 1986, vol. 2, p. 131.

31. Alekseev, S.A., Zaitsev, V.M., and Fraissard, J., Russ. Shem. Bull., 2003, vol. 52, no. 2, p. 364. 
32. Zaitsev, V.N., Kobylinskaya, N.G., Kostenko, L.S., and Gerda, V.I., J. Anal. Chem., 2008, vol. 63, no. 8, p. 779 .

33. Marczenko, Z., Kolorymetryczne Oznaczanie Pierwiastkow (Colorimetric Determination of Elements), Warszawa: Wysdawnictwa Naukowo-Techniczne, 1968.

34. Nishioka, T., Yuan, J., Yamamoto, Y., Sumitomo, K., Wang, Z., Hashino, K., Hosoya, C., Ikawa, K., Wang, G., and Matsumoto, K., Inorg. Chem., 2006, vol. 45, p. 4088.

35. Lian, N., Tang, J., He, X., Li, W., and Zhang, G., J. Anal. Chem., 2016, vol. 71, no. 7, p. 653.

36. Yagodin, G.A., Sinegribova, O.A., and Chekmarev, A.M., Tekhnologiya redkikh metallov $v$ atomnoi tekhnike (Technology of Rare Metals in Nuclear Engineering) Gromov, B.V., Ed., Moscow: Atomizdat, 1974.

37. Rard, J.A., Chem. Rev., 1985, vol. 85, no. 6, p. 555.

38. Andolina, C.M., Mathews, R.A., and Morrow, J.R., Helv. Chim. Acta, 2009, vol. 92, no. 11, p. 2330.

39. Şanli, S., Şanli, N., and Alsancak, G.A., J. Braz. Chem. Soc., 2009, vol. 20, no. 5, p. 939.

40. Gu, Ch., Karthikeyan, K.G., Sibley, S.D., and Pedersen, J.A., Chemosphere, 2007, vol. 66, p. 1494.

41. Tikhomirova, T.I., Smirnov, V.S., and Bystrov, V.Yu., Moscow Univ. Chem. Bull., 2008, vol. 63, no. 5, p. 288.

Translated by E. Rykova 